\title{
Digitalizing the Process of Tracking Technical Condition of the Main Equipment of Energy Providing Enterprises
}

\author{
Lyudmila Plotnikova ${ }^{1,{ }^{*}}$, Artem Bainov ${ }^{1}$, Yulia Torkunova ${ }^{1}$, and Maria Nadezhdina ${ }^{1,2}$ \\ ${ }^{1}$ Kazan State Power Engineering University, 420066 Kazan, Russia \\ ${ }^{2}$ Russian International Academy of Tourism, 420061 Kazan, Russia
}

\begin{abstract}
The existing power facilities of the Republic of Tatarstan face a number of disadvantages related to the system for recording data on the technical condition of boiler and turbine equipment: manual calculation of the parameters of equipment operation, lack of direct access to complete information on the condition of equipment and, as a result, low efficiency in identifying malfunctions, deviations in the operation of equipment, carrying out repair work. Hence, the need for digitalization of the system for recording data on the technical condition of equipment was formed, in response to which software was developed for automating the data recording system and visualizing the technical parameters of reliability at thermal power plants. This proposal is distinguished by the introduction of digital technologies in the process of recording data on the technical condition of equipment, where for the first time the software includes a method for automatically calculating the technical condition index of boiler units. The results of the work will reduce the likelihood of an emergency state of power plant equipment.
\end{abstract}

\section{Introduction}

The energy industry is engaged in the production of heat and electricity; the main role in this process is played by thermal power plants (TPPs). The main power generating units of TPPs are steam boilers (boiler units) and steam turbines (turbine units) [1-3]. They determine the performance of the entire thermal power plant. If the equipment fails and the necessary measures to resolve the emerged emergency are not taken in time, then the probability of a decrease in the plant's performance, up to the suspension of work, increases. Thus, the issue of operational monitoring of the technical condition of all operating equipment and identifying problems with a minimum amount of time is relevant [4-5].

The existing power facilities of the Republic of Tatarstan face a number of disadvantages related to the system for recording data on the technical condition of boiler and turbine equipment: information is entered into the database manually; calculations are

*Corresponding author: mikhailovalv@mail.ru 
carried out in Microsoft Excel; there is no single database for permanent viewing of reports; coordination of reports and their transfer between employees is difficult and timeconsuming; correction of inaccuracies in the lists asynchronously; correction and correction of data is difficult and takes more time; there is no possibility of forming statements online for any month and year; difficult control of equipment accounting.

As a result of the analysis of the situation, there was a need for digitalization of the system for recording data on the technical condition of boiler and turbine equipment, in response to which software was proposed and developed for automating the system for recording data on the technical condition of TPPs equipment and visualization of technical reliability parameters at thermal power plants.

Thus, the purpose of developing a software application module is to ensure control of the technical condition of the main equipment of TPPs (boiler units). Visualization of technical parameters for making management decisions in order to increase the efficiency and reliability of the main equipment. It is proposed to use the software to lay down a methodology for determining the technical condition index (TCI) of equipment. During the development of the software, the programming language JavaScript, the React.js library were used.

\section{Methodology for Developing Software for Tracking the Equipment Technical Condition}

The specialists of the branches of Tatenergo JSC draw up statements, which include the parameters of the technical condition of the equipment, their value under normal technical condition. The specialist enters the actual parameters and compares them with the reference ones. If a deviation is noticed, then the parameter is selected as an excess of the reference value. In addition to the parameters, a technician also enters information about the dates of the repairs and the measures taken to eliminate the problems.

Assessment of the technical condition of the equipment is carried out by comparing the actual values of the parameters of the functional unit with the rated values required by the documentation. All parameters of the technical state of functional units and general parameters are assessed on a 4-point scale for assessing the deviation of actual values from the reference ones, which are fixed by the documentation [4]. This scoring scale describes a qualitative assessment of the parameters of the technical state of functional units. Table 1 shows its ranges.

The calculation of the TCI of functional units begins with a comparison of the actual parameter of a functional unit from the n-th group of parameters with the norm and determining the score on a qualitative assessment scale. It is also necessary to determine the weighting factor for the $n$-th group of parameters [6-8].

Table 1. Ranges of the point scale for the qualitative assessment of parameters.

\begin{tabular}{|c|l|}
\hline Score & \multicolumn{1}{c|}{ Qualitative parameter assessment } \\
\hline 0 & Actual parameters are outside the zone of maximum permissible values \\
\hline 1 & $\begin{array}{l}\text { Actual parameters are in the zone of maximum permissible values, but the equipment does } \\
\text { not perform the required functions in full }\end{array}$ \\
\hline 2 & $\begin{array}{l}\text { Actual parameters are in the zone of maximum permissible values, but the equipment is } \\
\text { likely to fail }\end{array}$ \\
\hline 3 & $\begin{array}{l}\text { Actual parameters are in the zone of maximum permissible values, but the parameter value } \\
\text { is likely to worsen }\end{array}$ \\
\hline 4 & $\begin{array}{l}\text { Actual parameters do not deviate from the reference ones, the equipment operates at full } \\
\text { capacity and performs as intended }\end{array}$ \\
\hline
\end{tabular}

The formula for calculating TСI of functional units (ИТСУ) (1): 


$$
\text { ИТСУ }=100 \cdot \sum n(\text { КВ } n * \text { БАЛЛ } n) / 4,
$$

where БАЛЛ $n$ is the scoring of the parameter of the functional unit of the $n$-th group of parameters;

$\mathrm{KB} n$ is the value of the weighting factor for the $\mathrm{n}$-th group of parameters, in accordance with the documentation.

The formula for calculating the TCI (ИТС) of a unit of the main process equipment (2):

$$
\text { ИТС }=\sum \text { ИТСУ } n \cdot \operatorname{КВУ~} n,
$$

where ИТСУ $n$ is the TСI of the n-th functional unit or generalized unit;

$\mathrm{KBY} n$ is the value of the weighting factor for the $\mathrm{n}$-th functional unit or generalized unit, in accordance with the documentation.

The formula for calculating the TCI of the main equipment (3):

$$
\text { ИТС }=\sum_{n=0}^{m} \quad \text { ИТСУ } n,
$$

where ИТСУ $n$ is the ТСI of a unit of the main process equipment; $n$ is the number of functional units.

Evaluation of the calculation result of the TCI of the main equipment is necessary to determine the need for technical impact [6-8]. Table 2 shows measures of technical impact are given based on the assessment of equipment TCI.

Table 2. Measures of technical impact.

\begin{tabular}{|c|c|c|}
\hline TCI range & Technical condition assessment & Type of technical impact \\
\hline$\leq 25$ & Critical & $\begin{array}{c}\text { Immediate decommissioning, reconstruction and } \\
\text { re-equipment }\end{array}$ \\
\hline $25<$ and $\leq 50$ & Unsatisfactory & $\begin{array}{c}\text { Close control of equipment operation, } \\
\text { continuous maintenance and repair }\end{array}$ \\
\hline $50<$ and $\leq 70$ & Satisfactory & $\begin{array}{c}\text { Moderate control of equipment operation, } \\
\text { reconstruction }\end{array}$ \\
\hline $70<$ and $\leq 85$ & Good & $\begin{array}{c}\text { Taking the necessary measures based on the } \\
\text { results of routine diagnostics of equipment }\end{array}$ \\
\hline $85<$ and $\leq 100$ & Very good & Scheduled equipment diagnostics \\
\hline
\end{tabular}

\section{Results of Software Product Development}

The final software product is a one-page web application for keeping records of the technical condition of the main equipment of TPPs.

The following general requirements were set for the software product: input, storage, correction of the information; user authorization; generation of reports (annual, monthly); calculation of TCI (technical condition index) of boiler units; keeping records of equipment malfunctions; organization of the report approval process; sending and receiving notifications.

A software application consists of three main layers, namely the user interface (UI) presentation layer, the business logic layer, and the inner data access layer.

The module of the software application provides the following features that provide input, storage and correction of data: data input into the forms of statements, calculation of TCI and failures; storing data entered in forms; correction of the data entered in the forms.

The application provides mechanisms for user authentication and differentiation of access rights to data in order to avoid leakage or loss of important information.

After authorization, the user opens the main interface, it consists of the upper toolbar, which includes 6 buttons: "My account", "Select branch and equipment" (КТЭЦ-1 Вoiler unit No. 6), "Reports", "Technical condition index", "Equipment failures", "Settings". The 
name of "My account" tab displays the number of new notifications about the approval of reports. When the user interacts with any of the tabs on the screen, the page content will change (Fig. 1).

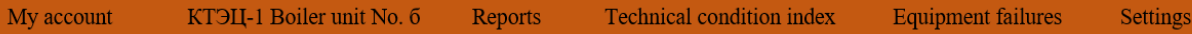

Fig. 1. Navigation bar for using the application.

"Select branch and equipment" tab provides an opportunity to select a branch of Tatenergo JSC (КТЭЦ-1, КТЭЦ-2, НЧТЭЦ, ЗГРЭС) and equipment (boiler units). The vertical table allows you to select a branch. When you click on a branch, the table is filled with boilers from this branch. When you click on the equipment, the name of the "Select branch and equipment" tab changes to the name of the branch and the name of the equipment (КТЭЦ-1 Boiler No.6) (Fig. 2).

\begin{tabular}{|c|c|c|c|c|}
\hline КТЭЦ-1 & Boiler unit No. 1 & Boiler unit No. 2 & Boiler unit No. 3 & Boiler unit No. 4 \\
\hline $\begin{array}{l}\text { КТЭЦ. } 2 \\
\text { НЧТЭЦ }\end{array}$ & Boiler unit No. 5 & Boiler unit No. 6 & Boiler unit No. 7 & Boiler unit No. 8 \\
\hline ЗГРЭС & Boiler unit No. 9 & Boiler unit No. 10 & Boiler unit No. 11 & Boiler unit No. 12 \\
\hline
\end{tabular}

Fig. 2. "Select branch and equipment" tab.

"Reports" tab allows the user to fill in and view reports on the technical condition of TPP equipment. "Fill in report" switches the system to the mode of filling the monthly report, and the button "View report" switches the system to the mode of reading the reports (Fig. 3). 


\begin{tabular}{|c|c|c|}
\hline Technical condition & Parameter & \\
\hline Steam-production capacity & Standard & 0 \\
\hline & Actual & 213 \\
\hline Feed water temperature & Standard & 1 \\
\hline & Actual & 2 \\
\hline & Standard & 2 \\
\hline Air inflow to firebox & Actual & 2 \\
\hline & Standard & 3 \\
\hline Air inflow to gas path & Actual & 3 \\
\hline Boiler gross efficiency & Standard & 4 \\
\hline & Actual & 4 \\
\hline Specific electric power & Standard & 5 \\
\hline consumption for thrust and & \begin{tabular}{|l} 
Actual \\
\end{tabular} & 5 \\
\hline Gas path resistance & Standard & 6 \\
\hline & Actual & 7 \\
\hline PR/PD rate & Standard & 7 \\
\hline & Actual & 8 \\
\hline & Standard & 8 \\
\hline Air excess ratio & Standard & 90 \\
\hline Exhaust gas temperature & Standard & 9 \\
\hline & Actual & 11 \\
\hline & Standard & 10 \\
\hline Fume gas $\mathrm{NOx}$ content & Actual & 10 \\
\hline Fuel (gas, fuel oil) & & Gas \\
\hline & & Fuel oil \\
\hline & & \\
\hline
\end{tabular}

Deviation reason Steam-production capacity

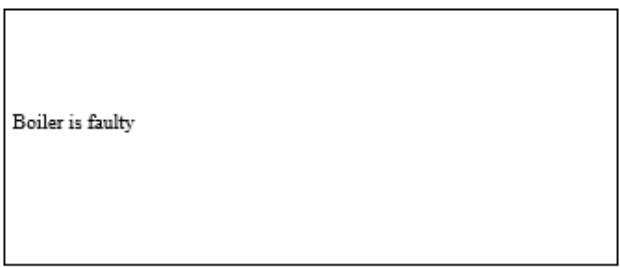

Measures to eliminate troubles Steam-production capacity

Replace parts to eliminate boiler failure

Planned date of elimination: 06.05 .2020

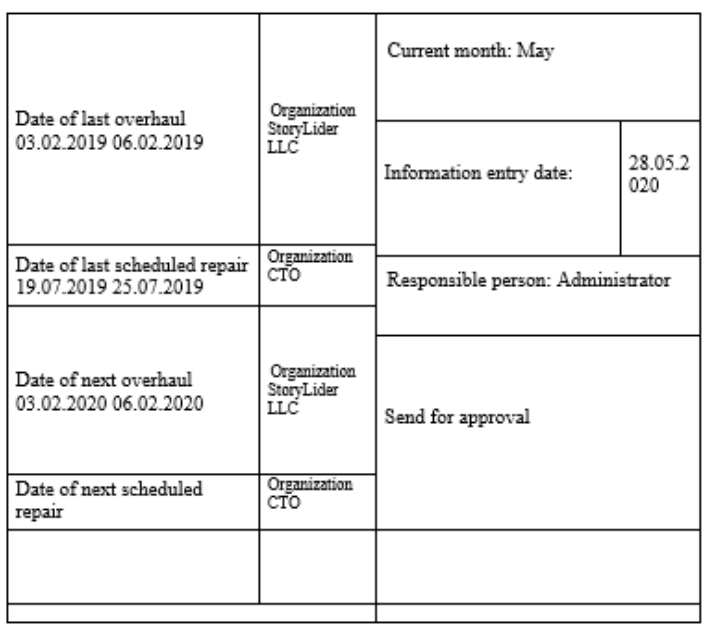

Fig. 3. "Reports" tab, filling mode.

"Technical condition index" tab (Fig. 4) allows the user to calculate the TCI of boiler units and view reports on the calculation for any month and year. "Calculate TCI" and "View TCI" buttons are provided.

The functional units are divided into 14 groups of modular units, which, in turn, are divided into 25 parameters. Each parameter has an input field or parameter selection list. When the parameter value is changed, the score is calculated by means of the score criterion, and based on the smallest value in the group, the TCI of the parameter is calculated. Further, the index of the parameter group is calculated based on TCI in percentage terms, which is translated into the total number of TCI of the parameter group. All final indices of the groups are summed up and the final value of the TCI of the boiler unit is obtained. The score for each parameter is calculated according to the criteria described in the "Methodology for assessing the technical condition of the main process 
equipment and power lines of power plants and electrical networks", approved by order of the Ministry of Energy of the Russian Federation No. 676 dated July 26, 2017. If the parameter is outside the range of maximum permissible values, the corresponding signs

and are displayed, otherwise the sign is displayed. "Hide functional unit group" button is available.

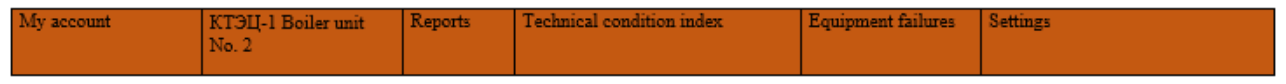

Calculate TCI View TCI

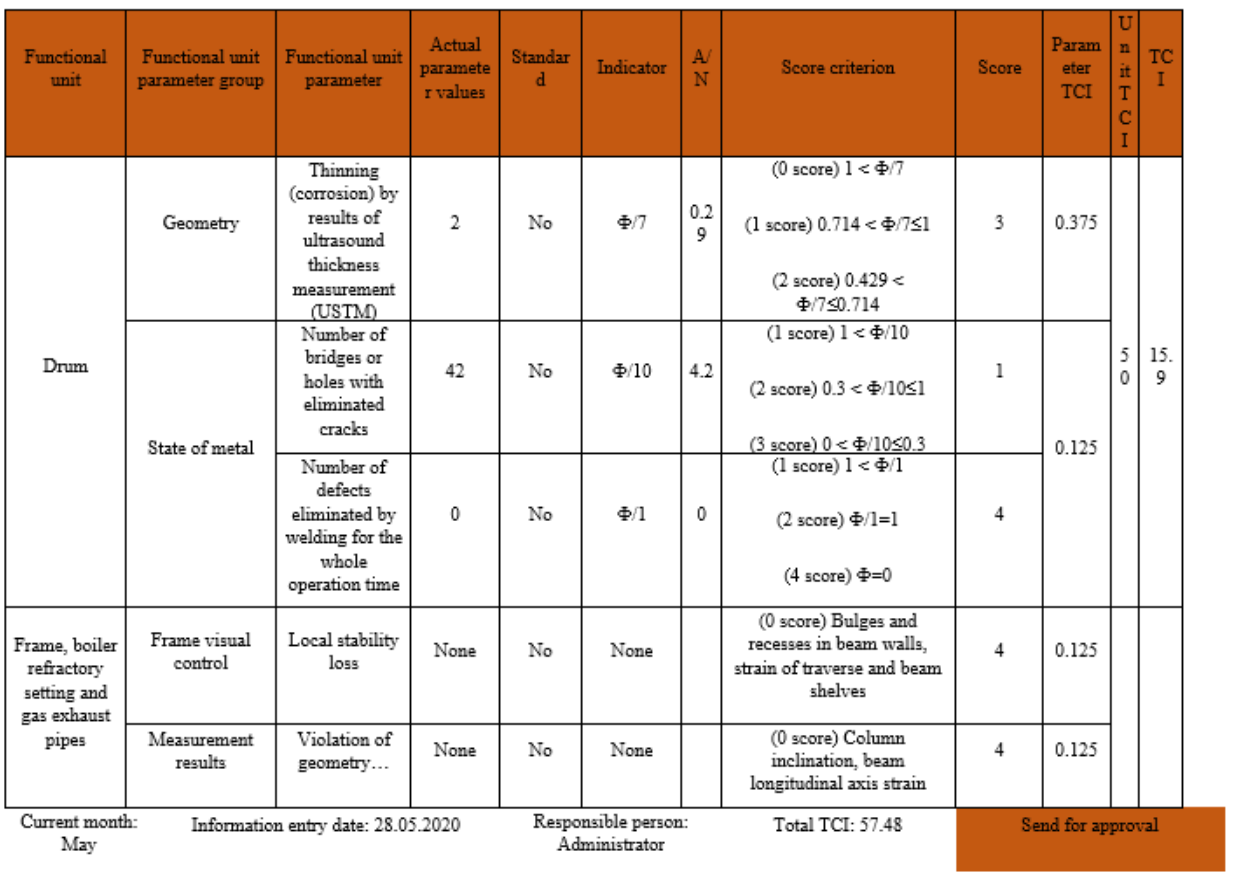

Fig. 4. "Technical condition index" tab, TCI calculation mode.

\section{Conclusions}

1. The results of the development of the software product is the implementation of the declared functions of the application and the differentiation of access rights for users. A software application module was created using the open source React.js library. The application has 4 work scenarios: administrator, manager, curator, branch specialist.

2. The mechanisms for filling and viewing the lists of the technical condition of the boiler unit parameters have been implemented. Also, a mechanism for calculating the technical condition index of the boiler unit and the ability to view TCI calculations were implemented. Filling in and viewing information about emergency situations of boiler units. Mechanisms for coordinating reports and notifications were implemented. A flexible setting of application administration for the "Administrator" user has been created. 
3. Thanks to the feature of the React.js library, creating a VirtualDOM tree and dynamically changing only individual parts of the real DOM tree, it allowed to achieve better performance for a high-load application.

4. The software ensures the reduction of equipment downtime, as well as a decrease in the likelihood of failure or critical breakdown of boiler units. Information about the technical condition of boiler units is filled in once a month. Before the implementation of the software, it took on average 3 to 4 days to obtain information and make management decisions. After the expected implementation of the software, access to new information will appear on the day of the monthly check of the technical condition of the equipment, due to which the time for making decisions on repair or suspension of work will be reduced to 1-2 days. Thus, the probability of critical breakdown and failure of the main equipment of the TPPs will be reduced by $32 \%$ while waiting for a management decision.

\section{References}

1. E.V. Paradnik, Information systems and technologies: management and security, $\mathbf{1}$ (2012)

2. O.A. Izotova, Electricity, 6 (2015)

3. O.I. Osipov, A.S. Karandaev, V.R. Khramshin, T.R. Khramshin, Electrical Engineering, 1 (2017)

4. A.O.Malahov, A.R.Zagretdinov,Sh.G. Ziganshin, Yu.V.Vankov, Journal of Physics: Conference Series, 1328(1) (2019)

5. I.V.Shvetsov, Yu.V.Vankov, A.R. Zagretdinov, IOP Conference Series: Materials Science and Engineering (2018)

6. E.A. Gavrilyuk, S. A. Mantserov, A. Yu. Panov, Basic research, 7-2 (2015)

7. A.V. Cherezov, E.P. Grabchak, Energy sector reliability and safety, 2(33) (2016)

8. S.V. Mishcheryakov, Energy sector reliability and safety, 11(2) (2018) 